duties under great difficulties, and without the status, the authority, or the salary of a Government astronomer. The Public Service Board recommended the removal of the observatory to a more suitable locality, on an eminence not too far from the capital; the appointment of an astronomer with high scientific attainments at a suitable salary ( $800 l$. per annum and a residence); the re-equipment with modern instruments, including a large telescope of not less than ${ }^{5} 5$ inches diameter; and that steps be taken to affiliate the observatory and the university. Whilst the latter recommendation has given rise to some difference of opinion, there is no dissension on the question of the necessity and advisability of re-establishing the observatory on a proper basis, so that New South Wales shall not be behind other States and countries in the prosecution of astronomical research. But the minds of the Ministers responsible are occupied with "important" matters!

The Spectra of Spiral. Nebule and Globular Star Clusters.-On May 20, 1909 (vol. lxxx., p. 354) we directed attention in these columns to some interesting results, obtained by Mr. Fath at the Lick Observatory, concerning the probable structure of spiral nebulæ and globular clusters as indicated by their several spectra. A second paper by the same author appears in No. x, vol. xxxiii., of The Astrophysical Journal, as a contribution (No. 49) from the Mount Wilson Solar Observatory.

For this later research $\mathrm{Mr}$. Fath employed a spectrograph attached to the 6o-inch reflector, and obtained spectra that are but little longer than $3 \mathrm{~mm}$. between $\lambda \lambda 3700$ and 5000 ; despite their small scale, these spectra afford further evidence as to the probable structure of the objects under consideration.

The spectrum of the spiral nebula N.G.C. $650-65 \mathrm{I}$ shows seven bright lines, at $373,387,397,434,486,496$, and 5 o I $\mu \mu$, corresponding to lines usually found in the spectra of gaseous nebulæe. N.G.C. 4725 gave a spectrum of the solar type with lines at $\mathrm{F}, \mathrm{G}, \mathrm{H}$, and $\mathrm{K}$, and a spectrum of N.G.C. 4736 is similar, with lines at $F, G, 425 \mu \mu$, $410 \mu \mu, \mathrm{H}, \mathrm{K}$, and $387 \mu \mu$. 1t is, however, a curious fact that the last-named spectrum differs considerably from one of the same object securcd in the earlier research the Mount Hamilton plate gave what was assumed to be a brisht band at $406 \mu \mu$, and absorption lines at 387 and $400 \mu \mu$, but as it was not in good focus other plates will be taken with a new specially designed spectrograph which, it is hoped, will be constructed shortly.

Whilst recognising that the evidence is, as yet, slight, Mr. Fath suggests that these results point to a progressive change in the spectra of nebula with change of form Starting with irregular nebule, like that in Orion, giving bright-line spectra, we pass to probable spiral nebula such as $\mathrm{N}$.G.C. $650-1$, where the spectrum shows bright lines and little or no continuous background, thence to planetary nebulx, such as N.G.C. 6543, giving the bright lines and considerable continuous spectrum. In the fourth type the spiral form is well developed, e.g. N.G.C. I068, and the spectrum, while still showing bright lines, has also a strong continuous spectrum, and contains absorption lines. The last type, exemplified by the Andromeda nebula, gives spectra of the solar type, and the nebula has condensed, at least partially, to stars. This progression indicates starclusters as the final product.

The spectra of eight globular clusters are almost identical, of approximately the $F$ type, in which the hydrogen series predominates, but, where the spectrum extends far enough, $\mathrm{H}$ and $\mathrm{K}$ are also found; a line, or band, near $4 \mathrm{rg} \mu \mu$ is also a common feature. In the Mount Hamilton plates, the Hercules cluster, N.G.C. 6205 , gave evidence of the inclusion of more than one type of spectrum, but the more recent work does not support this ; more plates with the slit crossing different parts of the cluster must be obtained.

The Dark Borders of the Martian Snowcaps.-In No. 4472 of the Astronomische Nachrichten, M. Antoniadi reverts to the question of the objective reality of the dark bands which appear to encircle the Martian polar caps. In a previous communication he maintained that, if real, they should show on photographs, but Prof. Lowell and others suggested that the brightness of the caps was so intense that the non-appearance of the dark areas might be accounted for by the photographic halation from the brilliant caps. This suggestion was supported by the statement that the photographs taken in America in 1909 showed the caps to be far more brilliant than the "continents." M. Antoniadi now brings independent testimony countering the statement, and maintains that the dark areas are not obliterated by photographic "spreading." In opposition to M. Jonckheere's contention that the dark bands exhibit the perspective they should do, if real, he states that he has never seen it, and reproduces a drawing made by Schiaparelli in 1884 in which the dark band is shown of equal breadth at the middle and at the ends of its maior axis.

Double-Star ObServations.-Nos. 4479-8o of the Astronomische Nachrichten contain a large number of double-star observations made by Dr. Doberck at Sutton, Surrey. Most of the observations were made in roro, and since 1010.13 the Elizabeth Thompson micrometer has been employed. In determining the scale value, corrections have been applied for aberration, refraction, and proper motion, and the final value obtained is $19 \cdot 342^{\prime \prime}+0.002^{\prime \prime}$.

No. 6, vol. iv., of the Journal of the Roval Astronomical Society of Canada contains a number of double-star measures made by Mr. Motherwell with the I5-inch refractor of the Dominion Observatory. 'The work was commenced in 1907 , the programme being to measure such pairs in Burnham's General Catalogue as are otherwise neglected or of which the motion seems uncertain.

The "Anvario" of the Madrid Observatory.-The annual almanac published by the Madrid Observatory contains the usual tables and ephemerides for the sun, moon, and planets, and a number of extra tables, in which information as to the aspect of the sky, the azimuth of the pole star, and the passages of certain stars, \&c., at given hours, is incorporated. Extensive tables for the calculation of latitude from observations of the pole star are also given, and the volume (IgII) concludes with records of the solar and meteorological observations made during 1909.

\section{THE NATIONAL PHYSICAL LABORATORY DURING I9Io.}

THE General Board of the National Physical Laboratory beld its annual meeting at the laboratory on Friday last, March 17, when the report of the executive committee for the year 1910 was formally presented. As usual, a large number of visitors were invited, and were received by Sir Archibald Geikie, president of the Royal Society and chairman of the General Board of the laboratory, and by Lord Rayleigh, the chairman of the executive committee.

The reception this year took place in the buildings of the National Experimental Tank, where the equipment for the experiments to be undertaken on models of ships is now almost complete. The models, 20 feet in length, are cast in clay moulds, and shaped to the correct form by a special machine, which cuts in them a scries of horizontal grooves, the operator guiding a tracing point over a corresponding sectional drawing. The wax is then trimmed down by hand to a smooth surface, leaving only the finest trace of the grooves as a suarantee of accuracy. The model is finally measured up on a special measuring table.

The carriage by which the model is towed along the tank weighs some ${ }_{5} 5$ tons, and is driven by four motors designed to enable a speed of $x y$ miles an hour to be reached for the steady portion of the run. As is well known, the "model " law requires that the speed shall be proportional to the square root of the linear dimensions, and the speed indicated is therefore more than sufficient for the purposes of the tests.

The first report of the advisory committee for the tank appears in the report of the laboratory for the year Igro, and gives some interesting details of the construction, and, in an appendix, of the movements of the walls due to filling. A more complete account of the tank and its equipment, by the superintendent, Mr. G. S. Baker, will be presented to the Institution of Naval Architects at their meeting next month.

The visitors to the laboratory were also able to see the progress which has been made with the new buildings for metallurgy, for which the laboratory is indebted to the generosity of Sir Julius Wernher. In these ample accom-

NO. 2 I6o, VOL. 86] 
modation will be provided in the near future for this important and increasing branch of the laboratory's work. In the physics department, several interesting items of the year's work call for mention. The erection of the Lorenz apparatus, presented by the Drapers' Company as a memorial of Prof. Viriamu Jones, and constructed, by the kindness and generosity of Sir Andrew Noble, at the Elswick works of Sir W. G. Armstrong, Whitworth and Co., is now nearly completed. So far the running has been very satisfactory, the speed remaining constant within 5 parts in 100,000 , without regulation, for fifteen minutes. Only the marble cylinders on which the coils are wound now require to be put into place.

In April and May, I9Io, Mr. F. E. Smith visited Washington, as the representative of the laboratory, to take part in an international research on the silver voltameter and the Weston normal cell. A full report on the work will shortly be presented to the International Committee on Electrical Standards, which was constituted at the London conference of I908. The immediate result of the work has been the adoption of the value 1.0183 international volts, in place of $x \cdot 0.84$, as the electromotive force of the Weston normal cell (see Nature, February I6, p. 508$)$.

The valuable researches on the construction and accurate measurement of inductances, which have now extended over several years, have been continued; an interesting feature of the recent work has been the construction of a resistance box of constant and almost negligible inductance. A comparison of magnetic tests, for total loss, on steel sheet is in progress, in cooperation with the Bureau of Standards at Washington and the Physikalisch-Technische Reichsanstalt.

The electrotechnics division has made investigations into the effect of travelling on supply meters, the heating of lamp sockets, the electric strength of micanite, and into the deterioration, and possible means of protection, of ebonite surfaces, which all present matter of considerable practical value. Tests on the heating of cables have been carried out for the Wiring Rules Committee of the Institution of Electrical Engineers. In photometry, the establishment of metallic filament sub-standard lamps has required an inrestigation which has presented numerous difficulties, and furnished results of much theoretical and practical interest. An important comparison of life tests of glow-lamps was carried out between the laboratory and the Electrical Testing Laboratories of New York, and showed that agreement within 5 per cent. could be expected in such tests.

In the work on the fundamental high-temperature scale, difficulties have been met with in the construction of the reservoirs and tubes of refractory rare-earth materials, which for the time have delayed progress. Valuable work has been done for the International Commission which is dealing with the methods and apparatus for petroleum testing. It is well known that different forms of flashpoint apparatus give different values for the flash-point of an oil. Careful exploration of the temperatures below and at the oil surface, and in the vapour, up to the time of flash, has indicated a probable cause of these discrepancies. Some interesting tests have been carried out on the Siemens' calorimetric water pyrometer.

In the metrology division, Mr. J. E. Sears has taken over the charge of the work from Mr. H. H. Jeffcott, who was appointed early in rgro to the professorship of engineering in the Royal College of Science, Dublin. An interesting feature of the year's work has been the study of the thermal expansion and hysteresis of fused silica, in connection with the new silica standard of length. An account of this work, and of a method employed for counting the rulings of a diffraction grating, has been prepared by Dr. Kaye, and published in the Philosophical Magazine.

In the optics division, a tilting table of special design has been installed for tests on clinometers and levels, and metal prisms to serve as standards of angle have been made for use with it, their angles being measured by optical means to a high degree of accuracy.

In the engineering department, a large number of researches have been further advanced, among which may be mentioned specially the investigation into the strength and efficiency of welded joints, the work on alternating stresses of high frequency, shock tests on different forms of screw threads, and the research on the heat transmission and friction of air currents in pipes. In the aëronautics section much interestins work has also been done. The investigations in the air and water channels have dealt with the resistance, stability, and fin area of dirigibles, the lift and drift and centre of pressure of curved surfaces for use as rudders or for other purposes, the resistance of wires, stationary and vibrating, and of ropes, as well as of radiators, model gondolas, \&c. The propeller test results have been improved by a careful investigation of the motion set up in the air of the whirling-table shed due to the inotion of the whirling arm. The tests of motors entered for the Alexander prize, together with the construction of the necessary testing plant, also formed an important feature of the year's work. The report on these tests was published in November last.

The chief metallurgical research concluded during the year rgro was that on the aluminium-copper-manganese alloys, which formed the subject of the ninth report to the Alloys Research Committee of the Institution of Mechanical Engineers. Work on the alloys of aluminium and zinc has since been in progress, and an interesting paper on the theoretical results of this research has recentiy been communicated to the Royal Society. The investigations into the eutectic alloys, and into the effect of strain on steel at high temperatures, have also made good progress. The planning of the new metallurgical laboratories has, of course, constituted an important part of the year's work.

The section of the report which deals with the work of the observatory department gives details as to the tests of instruments during 1910 , and also some particulars of the growth of the Kew verification work between 1880 and 1910. The number of "clinicals" tested in $188 \mathrm{I}$ was about 4000 , in 1909 nearly 26,000 . The total number of instruments tested since 1880 is more than 673,000 . In July last the meteorological work of $\mathrm{Kew}$ was transferred to the Meteorological Office, of which Kew will in future be the central observatory.

The complete scheme of reorganisation of the Kew work involves the transference to Teddington of the instrument testing, but for this increased accommodation at Teddington is necessary. The great growth of the work of the laboratory renders also imperative the provision of a building for office and administration purposes. The plans for these additional buildings are already well advanced, and it is earnestly to be hoped that lack of funds will not be allowed to hamper and to curtail the natural development of the important work which the laboratory is called upon to undertake. Figures published in the laboratory report for Ig Io show that, out of a total capital expenditure of about ro3,00ol., 49,00ol. is due to Government grants, while 54,00ol. has been received from private sources and as payment for work done; and in view of these figures the committee urge that the request for funds for the much needed extension is one which deserves most favourable consideration from the Treasury.

The preceding paragraph is based on the report of the executive committee of the laboratory to the general board. We understand it was stated at the meeting that an intimation has just been received from the Treasury that the sum of $5000 l$. will be placed on the Estimates for roII-I2 towards the cost of the new buildings proposed. The recognition thus afforded of the importance of the work which the laboratory is doing is valuable, but the sum is clearly insufficient to enable the scheme which has been prepared, the estimated expense of which is about $20,000 l$., to go forward immediately. It is, of course, possible that some other generous donor may be found ready to assist the laboratory in its national work; the electrotechnics building was provided by a gift of $5000 \%$. from Sir John Brunner, Mr. A. F. Yarrow has enabled the national experimental tank to be constructed at a cost of 20,00ol., and, as already stated, Sir Julius Wernhe: has recently given io, oool. for the erection of the metallurgy building, while others have given large sums towards the equipment of the laboratory. It is to be hoped that the Royal Society and the governing board of the laboratory may find means which will.enable them to provide. without unnecessary delay, the additional buildings and accommodation rendered necessary by the rapid development of the work. 